\title{
Anti-enterococcal activities of pentacyclic triterpenes
}

\author{
Dorota Wojnicz, ${ }^{1, D}$, Dorota Tichaczek-Goska, B-D, Kamila Korzekwa ${ }^{2, B}$, Marta Kicia', B, Andrzej Hendrich', E,F \\ ${ }^{1}$ Department of Biology and Medical Parasitology, Wroclaw Medical University, Poland \\ ${ }^{2}$ Institute of Genetics and Microbiology, University of Wrocław, Poland \\ A - research concept and design; $\mathrm{B}$ - collection and/or assembly of data; C - data analysis and interpretation; \\ $D$ - writing the article; $E$ - critical revision of the article; $F$ - final approval of article
}

\section{Address for correspondence \\ Dorota Tichaczek-Goska \\ E-mail:dorota.tichaczek-goska@umed.wroc.pl \\ Funding sources \\ This research was supported by Wroclaw Medical University (project number 5-S/PD-SN/2011).}

\section{Conflict of interest}

None declared

Received on 0ctober 14, 2015

Revised on November 07, 2015

Accepted on March 17, 2016

DOI

10.17219/acem/62245

\section{Copyright}

Copyright by Author(s)

This is an article distributed under the terms of the

Creative Commons Attribution Non-Commercial License

(http://creativecommons.org/licenses/by-nc-nd/4.0/)

\begin{abstract}
Background. Asiatic (AA) and ursolic (UA) acids are widely studied phytochemicals, but their antimicrobial properties are still poorly understood. Therefore our research has focused on their activity against uropathogenic Enterococcus faecalis strains.
\end{abstract}

Objectives. The aim of this research was to determine the influence of AA and UA on the growth, cell morphology, virulence factors and biofilm formation by E. faecalis strains.

Material and methods. AA and UA were purchased from Sigma-Aldrich. E. faecalis strains were isolated from the urine samples of patients with urinary tract infections. The strains were checked for the presence of virulence genes using the PCR method. Their antimicrobial susceptibility was performed using the disc diffusion method. The MICs of triterpenes were determined using the broth microdilution method. The hydrophobicity of cells was established by salt aggregation test. Lipase and lecithinase activities were determined by using an agar medium containing egg yolk emulsion. DNase agar was used for the detection of DNase synthesis. Hemolytic activity was established using a sheep-blood agar. Todd-Hewitt agar medium containing gelatin was used for determination of gelatinase activity. The anti-biofilm activity of asiatic acid and ursolic acid was tested on polystyrene microtiter plates. It was examined using time-kill and biofilm assays.

Results. Reduction of growth and enzyme synthesis after exposure of E. faecalis to the acids was observed. None of the acids changed the hydrophobicity of bacteria. Stronger anti-biofilm activity was observed when the bacteria were incubated with AA. Thus, reduction of both the survival and the virulence factors will make bacteria less infectious.

Conclusions. Based on the results obtained, we can assume that the triterpenes investigated should be considered natural components of a human diet rather than as antibacterial agents used on their own.

Key words: Enterococcus faecalis, pentacyclic triterpenes, asiatic acid, ursolic acid, antimicrobial agents 
Pentacyclic triterpenes are secondary metabolites widely distributed in the plant kingdom. They are the subject of numerous phytochemical and pharmacological studies. Plants with a high content of pentacyclic triterpenes are often used in herbal medicine due to their valuable therapeutic properties. ${ }^{1}$ Asiatic acid $(2 \alpha, 3 \beta, 23-$ trihydroxyurs-12-en-28-oic, AA) and ursolic acid (3 $\beta$ hydroxyurs-12-en-28-oic, UA) belong to the group of pentacyclic triterpenes. AA is a secondary metabolite first found in medicinal plant Centella asiatica L. (Apiaceae). The leaves of this herb are used in the treatment of diverse human disorders. ${ }^{2,3} \mathrm{UA}$ is present in a wide variety of plants, such as: apple and grape peels, cranberries, lavender, rosemary, thyme, oregano, salvia, basil, leaves of yerba mate and many others. ${ }^{1}$ AA and UA have similar chemical formulas (Fig. 1), but they differ in the number of $\mathrm{CH}_{3}$ and $\mathrm{OH}$ groups.

Many studies have confirmed the antitumor, antioxidant, anti-inflammatory, antiviral, antiprotozoal, antidiabetic, antihyperlipidemic and anti-osteoporosic, as well as neuroprotective and hepatoprotective activities of pentacyclic triterpenes. ${ }^{2-6}$ However, there are only a few studies describing the antimicrobial effects of these compounds. ${ }^{7-9}$ Usually the studies focus on the determination of the minimal inhibitory concentration (MIC) values of the triterpenes. The influence of triterpenes on bacterial virulence factors has not yet been precisely described. Our previous studies have shown that AA and UA change the virulence of uropathogenic Escherichia coli strains. ${ }^{10-12}$ Impairment of the virulence factors decreases the pathogenicity of bacteria and thus reduces the development of infection.

Enterococcus faecalis is a gram-positive bacteria often associated with serious nosocomial infections of which urinary tract infections (UTIs) are the most widespread. These infections can be difficult to treat because of the frequent resistance of $E$. faecalis to multiple antibiotics. ${ }^{13}$ For this reason, the need for alternative solutions for UTI prophylaxis and treatment nowadays is more important than ever.

Therefore, the aim of our study was to establish the effect of AA and UA on growth, virulence factors and biofilm formation by uropathogenic E. faecalis strains isolated from urine samples of patients suffering from recurrent UTIs.

\section{Material and methods}

\section{Isolation and identification of bacterial strains}

E. faecalis strains $(\mathrm{n}=10)$ were isolated from the urine samples of ambulatory patients with urinary tract infections. Bacteria were identified using the API ID32-Strep system (bioMerieux, Poland). The isolates were maintained on Mueller-Hinton agar slopes (Oxoid, UK) at $4{ }^{\circ} \mathrm{C}$. To confirm the membership of the tested strains to E. faecalis a PCR was performed with primers specific for the E. faecalis species. ${ }^{14}$

\section{Antimicrobial susceptibility testing}

Antimicrobial susceptibility of E. faecalis strains was performed using the disc diffusion method on MuellerHinton agar according to CLSI. ${ }^{15}$ The following antibiotics were tested: ampicillin $(2 \mu \mathrm{g})$, gentamicin $(30 \mu \mathrm{g})$, trimethoprim/sulfamethoxazole (trimethoprim $1.25 \mu \mathrm{g}$ and sulfamethoxazole $23.75 \mu \mathrm{g})$, and nitrofurantoin $(100 \mu \mathrm{g})$. Bacteria were interpreted as susceptible or resistant according to the sensitivity zones of antibiotics as recommended by EUCAST. ${ }^{16}$

Fig. 1. Chemical structures of a) asiatic acid and b) ursolic acid. A, B, C, D, E - the names of rings in the molecules

a)

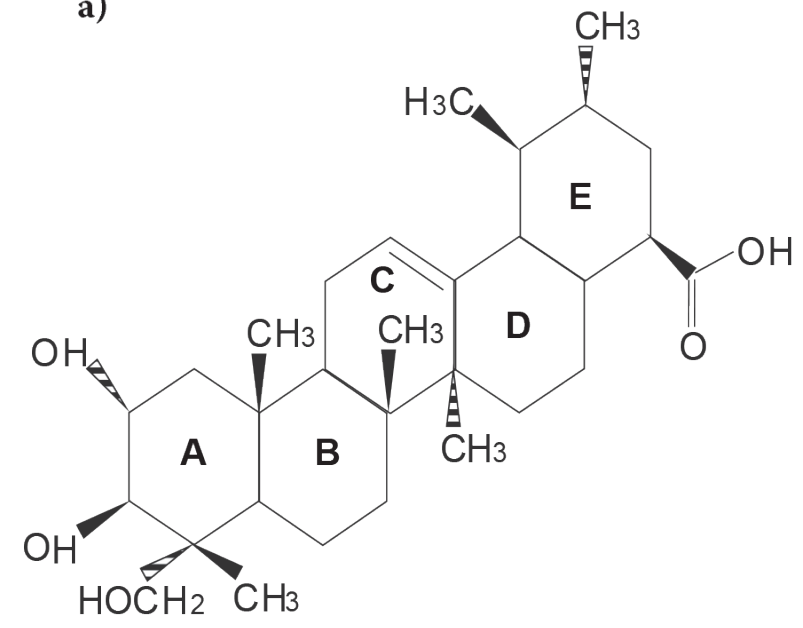

b)

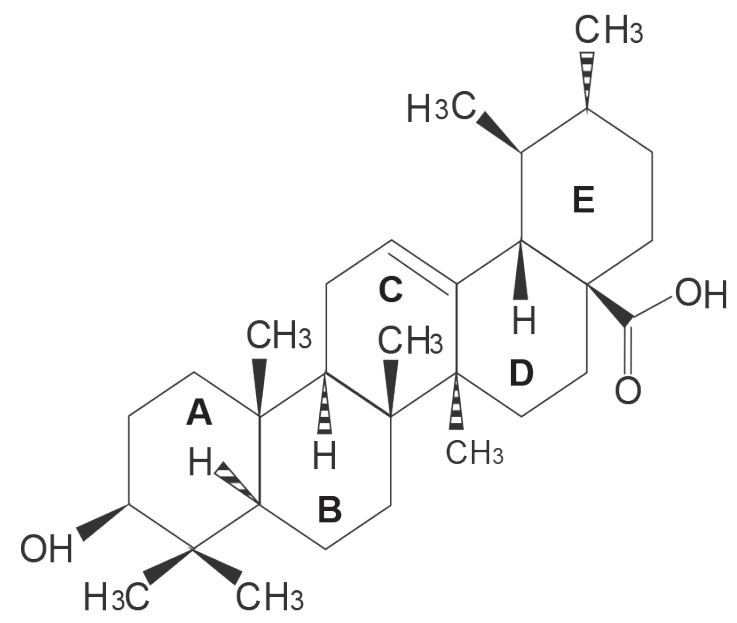




\section{Detection of virulence-related genes}

Bacterial DNA was obtained by using GeneMATRIX Bacterial \& Yeast Genomic DNA Purification Kit (EURx, Poland). The following virulence-related genes were amplified by PCR: gelE (gelatinase), esp (enterococcal surface protein), cylA (cytolysin activator) and cylB (cytolysin transporter), asa (aggregation substance) and ace (enterococcal adhesin to collagen). Specific primer sequences and expected amplicon sizes were described by Cosentino et al. and Creti et al. ${ }^{17,18}$ PCR amplification products were visualized and analyzed using the Quantity One Software (Bio-Rad, USA).

\section{Pentacyclic triterpenes}

Asiatic acid (AA, purity $\geq 97 \%$ ) and ursolic acid (UA, purity $\geq 90 \%$ ) were purchased from Sigma-Aldrich (Poznań, Poland) and dissolved in 96\% ethanol to obtain stock solution. For all experiments, acids were diluted with Mueller-Hinton Broth (MHB; Biocorp, Poland).

\section{Determination of minimal inhibitory concentration (MIC)}

The MICs of AA and UA were determined by the broth microdilution method recommended by the CLSI. ${ }^{15}$

\section{Effect of AA and UA on bacterial survival}

The strains were grown overnight, and then transferred to $\mathrm{MHB}$ and incubated at $37^{\circ} \mathrm{C}$ for $30 \mathrm{~min}$. Following incubation, the bacterial cells were centrifuged (4000 $\mathrm{rpm} / 20 \mathrm{~min}$ ) and suspended in PBS to reach the final density $1-2 \times 10^{8} \mathrm{CFU} / \mathrm{mL}$. The bacterial suspension and AA or UA were mixed together to obtain $0.75 \times$ MIC of triterpene in each sample. Samples were incubated at $37^{\circ} \mathrm{C}$ for $24 \mathrm{~h}$, then diluted and cultured on nutrient agar plates (Biomed, Poland). After 0, 2, 4, 6, and $24 \mathrm{~h}$ of incubation at $37^{\circ} \mathrm{C}$, the number of $\mathrm{CFU} / \mathrm{mL}$ was counted. Control samples contained no triterpenes.

\section{Effect of triterpenes on bacterial morphology}

E. faecalis strains were incubated at $37^{\circ} \mathrm{C}$ for $24 \mathrm{~h}$ with AA or UA at concentrations of $0.75 \times$ MIC. The bacterial samples were then washed 3 times in PBS. The final pellets were Gram-stained and observed under microscope (Nikon Eclipse 400). The changes in bacterial cell morphology were recorded.

\section{Effect of AA and UA on hydrophobicity of bacterial cells}

The bacteria were grown overnight at $37^{\circ} \mathrm{C}$ in the presence of $0.75 \times$ MIC of AA or UA. Next, the bacteria were harvested by centrifugation (4000 rpm for $20 \mathrm{~min}$ ) and resuspended in PBS to obtain a final optical density (measured at $470 \mathrm{~nm}$ ) of 1.0. The salt aggregation test (SAT) of ammonium sulphate was used. ${ }^{19}$ The lowest concentration of ammonium sulphate at which bacteria aggregated was determined. Based on the SAT values, the strains were classified as: $0.1-0.2 \mathrm{~mol} / \mathrm{L}$, very strongly hydrophobic; $0.4-1.0 \mathrm{~mol} / \mathrm{L}$, strongly hydrophobic; $1.2-1.6 \mathrm{~mol} / \mathrm{L}$, hydrophobic; $1.8-3.2 \mathrm{~mol} / \mathrm{L}$, hydrophilic.

\section{Effect of AA and UA on enzyme activity}

Lipase: Lipase activity was determined as described by Furumura et al. ${ }^{20}$ The appearance of an opaque zone around the well indicated lipolytic activity.

Lecithinase: To determine lecithinase synthesis, $0.02 \mathrm{~mL}$ of bacterial suspension was inoculated onto plates with agar containing $10 \%$ egg yolk emulsion and incubated at $37^{\circ} \mathrm{C}$ for $24 \mathrm{~h}$. The appearance of an opaque zone around the well indicated lecithinase activity. ${ }^{21}$

Hemolysins: The volume of $0.02 \mathrm{~mL}$ of bacterial suspension was spot-inoculated onto $5 \%$ sheep-blood agar plates and incubated at $37^{\circ} \mathrm{C}$ for $24 \mathrm{~h}$. Hemolytic activity was confirmed by the appearance of a clear zone around the bacterial colonies. ${ }^{22}$

Gelatinase: The volume of $0.02 \mathrm{~mL}$ of bacterial suspension was spot-inoculated onto Todd-Hewitt agar medium containing gelatin. Gelatinase production was confirmed by the appearance of a turbidity zone around the bacterial spots. ${ }^{23}$

DNase: For detection of DNase synthesis, $0.02 \mathrm{~mL}$ of bacterial suspension was cultured on plates with DNase agar (Oxoid, UK). After $24 \mathrm{~h}$ of incubation at $37^{\circ} \mathrm{C}$, the plates were flooded with $1 \mathrm{~mol} / \mathrm{L} \mathrm{HCl}$. Transparent zones around the colonies indicated DNase activity. ${ }^{24}$

\section{Effect of AA and UA on biofilm production}

The biofilm production assay was performed according to O'Toole and Kolter with slight modifications. ${ }^{25}$ Briefly, diluted cultures $\left(1-2 \times 10^{8} \mathrm{CFU} / \mathrm{mL}\right)$ were inoculated into a polystyrene plate's wells containing $0.2 \mathrm{~mL}$ of $\mathrm{MHB}$ and AA or UA at a concentration of $0.75 \times \mathrm{MIC}$. After incubation for $1-10$ days at $37^{\circ} \mathrm{C}$, the wells were rinsed. Bacterial cells attached to the plate's walls were stained with $1 \%$ (w/v) crystal violet (Sigma-Aldrich, Poland) and rinsed. The dye bound to bacteria was resolubilized with 95\% (v/v) ethanol. The optical density (OD) was measured at $590 \mathrm{~nm}$ (Infinite ${ }^{\circledR} 200$ PRO, TECAN, Switzerland). The ODc value was defined according to Stepanovic et al. ${ }^{26}$ In the current research, the ODc was 0.047. E. faecalis strains were classified as follows: OD $\leq$ ODc, no biofilm producer; ODc $<\mathrm{OD} \leq 2$ ODc, weak biofilm producer; 2ÍODc $<$ OD $\leq 4$ ODc, moderate biofilm producer; $\mathrm{OD}>4$ ODc, strong biofilm producer. ${ }^{26}$ 


\section{Bacterial survival in biofilm in the presence of AA or UA}

This experiment was done according to the method by Di Bonaventura et al. ${ }^{27}$ Bacterial survival in biofilms was assessed after 1-10 days. Bacterial cultures were washed to remove non-adherent cells. Biofilms were scraped and transferred into microtubes containing PBS and centrifuged to separate the cells from the biofilm matrix. Bacteria were plated onto nutrient agar plates and the CFU/mL was counted.

\section{Statistical analysis}

All values are expressed as a mean \pm SD of 3 independent experiments. Statistical differences between bacterial strains exposed to triterpenes and unexposed (controls) were analyzed by non-parametric Kruskal-Wallis test followed by a Dunn's multiple comparison test. All statistical analysis was performed using STATISTICA v. 12.0 (StatSoft, Poland). Values of $\mathrm{p}<0.05$ were considered statistically significant.

\section{Results}

In our study, ten clinical E. faecalis strains possessed virulence-related genes: gelE, esp, cylA, cylB, asa, and ace, which are important in the pathogenesis of enterococcal infections. ${ }^{28}$

All tested strains of $E$. faecalis demonstrated high level resistance to gentamycin (HLGR), 60\% were resistant to nitrofurantoin, $50 \%$ to ampicillin, and $40 \%$ to trimethoprim/sulfamethoxazole (Table 1).

The MICs of AA and UA against E. faecalis isolates are presented in Table 2. The MICs of AA were 64 and

Table 1. Susceptibility pattern of E. faecalis strains

\begin{tabular}{l|l|l|l|l|l|l|l|l|l}
\multicolumn{10}{c}{ E. faecalis strain No. } \\
\hline 3 & 4 & 9 & 11 & 38 & 51 & 69 & 71 & 80 & 83 \\
\hline
\end{tabular}

\begin{tabular}{|l|l|l|l|l|l|l|l|l|l|l|}
\hline Ampicillin & $\mathrm{R}$ & $\mathrm{S}$ & $\mathrm{S}$ & $\mathrm{S}$ & $\mathrm{R}$ & $\mathrm{R}$ & $\mathrm{R}$ & $\mathrm{S}$ & $\mathrm{S}$ & $\mathrm{R}$ \\
\hline Gentamycin & $\mathrm{R}$ & $\mathrm{R}$ & $\mathrm{R}$ & $\mathrm{R}$ & $\mathrm{R}$ & $\mathrm{R}$ & $\mathrm{R}$ & $\mathrm{R}$ & $\mathrm{R}$ & $\mathrm{R}$ \\
\hline $\begin{array}{l}\text { Trimethoprim/ } \\
\text { /Sulfamethoxazole }\end{array}$ & $\mathrm{S}$ & $\mathrm{S}$ & $\mathrm{R}$ & $\mathrm{S}$ & $\mathrm{S}$ & $\mathrm{R}$ & $\mathrm{S}$ & $\mathrm{S}$ & $\mathrm{R}$ & $\mathrm{R}$ \\
\hline Nitrofurantoin & $\mathrm{R}$ & $\mathrm{R}$ & $\mathrm{R}$ & $\mathrm{R}$ & $\mathrm{S}$ & $\mathrm{S}$ & $\mathrm{R}$ & $\mathrm{S}$ & $\mathrm{S}$ & $\mathrm{R}$ \\
\hline
\end{tabular}

$\mathrm{R}$ - resistant; $\mathrm{S}$ - sensitive.

Table 2. The MICs of AA and UA against E. faecalis strains

\begin{tabular}{|l|c|c|c|c|c|c|c|c|c|c|}
\hline & \multicolumn{10}{c|}{ E. faecalis strain No. } \\
\cline { 2 - 13 } & 3 & 4 & 9 & 11 & 38 & 51 & 69 & 71 & 80 & 83 \\
\hline $\mathrm{AA}(\mu \mathrm{g} / \mathrm{mL})$ & 128 & 64 & 64 & 128 & 64 & 64 & 64 & 64 & 64 & 64 \\
\hline $\mathrm{UA}(\mu \mathrm{g} / \mathrm{mL})$ & 64 & 64 & 64 & 64 & 512 & 256 & 128 & 32 & 128 & 64 \\
\hline
\end{tabular}

$128 \mu \mathrm{g} / \mathrm{mL}$. The MICs of UA were in the range of 32-512 $\mu \mathrm{g} / \mathrm{mL}$. No correlation was noticed when the susceptibility pattern and MIC values of pentacyclic triterpenes were compared.

In the current study, the effect of AA and UA on the growth of planktonic forms of E. faecalis was examined. The anti-growth effect of both triterpenes was observed after 2 , 4, 6 and 24 h of incubation (Fig. 2). The greatest activity of AA was noticed after $24 \mathrm{~h}$ (Kruskal-Wallis test, $\mathrm{H}=17.841$, $\mathrm{p}=0.0001$; Dunn's Multiple Comparison test, $\mathrm{p}=0.00007$ ). The survival of bacteria was decreased 250 -fold in comparison to the control sample (control $-37.5 \times 10^{7} \mathrm{CFU} / \mathrm{mL}$; AA $\left.-0.15 \times 10^{7} \mathrm{CFU} / \mathrm{mL}\right)$. The statistically significant bactericidal activity of UA was noticed after 2, 4 and $6 \mathrm{~h}$ of incubation (Kruskal-Wallis test, $\mathrm{H}=17.841$, $\mathrm{p}=0.0001$; Dunn's Multiple Comparison test, $\mathrm{p}=0.00007)$. The most reduced survival was observed after $6 \mathrm{~h}$ of incubation. The CFU/mL were $32.7 \times 10^{7}$ and $0.042 \times 10^{7}$ in the control and the sample with UA, respectively.

We also found alterations of the size and arrangement of bacterial cells in samples containing AA (Fig. 3). E. faecalis cocci cultured in presence of AA were bigger than those incubated in UA, and formed aggregates instead of chains, in comparison to untreated bacteria.

In the current study, we demonstrated that all clinical E. faecalis strains possess a very strong hydrophobic cell surface, which confirms the important role of this trait in non-specific mechanism of adhesion. Unfortunately, our experiments have shown that none of the acids changed the hydrophobic nature of the E. faecalis isolates.

We also determined the effect of AA and UA on the ability of $E$. faecalis strains to synthesize lipase, lecithinase, DNase, hemolysin and gelatinase.

As shown in Fig. 4a, AA significantly reduced the synthesis of lipase in 4 E. faecalis strains (Dunn's Multiple Comparison test, $\mathrm{p}<0.05$ ), and UA in 6 cases (Dunn's Multiple Comparison test, $\mathrm{p}<0.05)$. One of the tested strains significantly increased lipase production after the treatment by UA. The opaque zone diameters became wider in comparison with untreated bacteria (Dunn's Multiple Comparison test, $\mathrm{p}<0.001$ ).

In our study, 8 out of 10 strains synthesized lecithinase in control conditions. It is worth noting that AA significantly decreased production of this enzyme in 5 E. faecalis strains (Dunn's Multiple Comparison test, $\mathrm{p}<0.05)$ and completely inhibited its secretion in one case (Dunn's Multiple Comparison test, $\mathrm{p}<0.001$ ) (Fig. 4b). Two strains of cocci grown in the presence of UA completely stopped the synthesis of lecithinase (Dunn's Multiple Comparison test, $\mathrm{p}<0.001)$.

As shown in Fig. 4c, UA decreased the secretion of hemolysins in $4 \mathrm{E}$. faecalis strains (Dunn's Multiple Comparison test, $\mathrm{p}<0.05)$ and completely inhibited hemolytic activity in 3 cases (Dunn's Multiple 
Fig. 2. Effect of asiatic acid (AA) and ursolic acid (UA) on the growth of the planktonic forms of $E$. faecalis clinical strains. Values represent the mean \pm SD of three separate experiments for ten strains

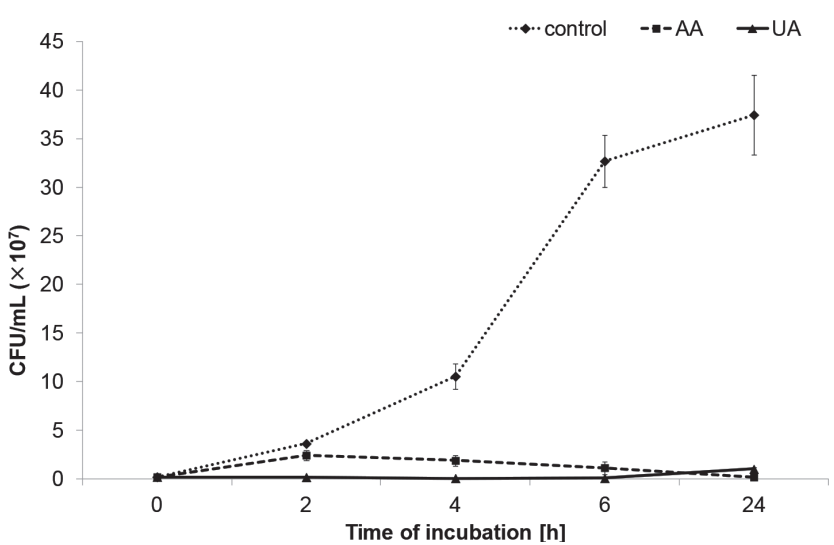

Comparison test, $\mathrm{p}<0.001)$. The anti-hemolytic activities of AA were significant in 5 E. faecalis strains (Dunn's Multiple Comparison test, $\mathrm{p}<0.05$ or $\mathrm{p}<0.001$ ).

In our study, 8 out of 10 strains synthesized gelatinase in control conditions (Fig. 4d). The anti-gelatinase effect of triterpenes was noted in the case of 5 strains incubated with AA and 2 strains incubated with UA (Dunn's Multiple Comparison test, $\mathrm{p}<0.05$ or $\mathrm{p}<0.001$ ).

The results of the current study showed that only 3 E. faecalis strains produced DNase. The synthesis of this enzyme was completely suppressed only in 1 isolate treated with UA (Dunn's Multiple Comparison test, $\mathrm{p}<0.001$ ).

The results showing the influence of AA and UA on biofilm formation by $E$. faecalis strains are given in Fig. 5a. The cultures of untreated E. faecalis strains incubated up to 10 days produced weak $(0.047<\mathrm{OD} \leq 0.094)$ or moderate $(0.094<\mathrm{OD} \leq 0.188)$ biofilm. The reduction of biofilm was observed when bacteria were incubated with AA during the whole time of observation. The mean OD values were $\leq 0.047$. There were significant differences between OD values of biofilm in the presence of AA and control samples after the $1^{\text {st }}, 7^{\text {th }}$ and $10^{\text {th }}$ days of incubation (Dunn's Multiple Comparison test, $\mathrm{p}<0.05$ or $\mathrm{p}<0.001)$. A weaker effect on the biofilm formation ability was exerted by UA. The OD values were lower compared to the control samples with the exception of the $2^{\text {nd }}, 3^{\text {rd }}$ and $8^{\text {th }}$ day. Bacteria incubated in the presence of UA still produced weak or moderate biofilm. The mean OD value was 0.039 . There were no significant differences between the OD values of biofilm in the presence of UA and control samples (Dunn's Multiple Comparison test, $\mathrm{p}>0.05$ ).

In our study, the bacterial survival in biofilm mass was determined after each time of incubation. As shown in Fig. $5 \mathrm{~b}$, the number of bacterial cells per $\mathrm{mL}$ has been decreased in cultures containing both AA or UA compared to control samples. In the biofilms formed in the presence of $\mathrm{AA}$, the $\mathrm{CFU} / \mathrm{mL}$ ranged from $0.003 \times 10^{7}$ to $0.107 \times 10^{7}$. The values of CFU/mL in the biofilms treated with UA was much higher and ranged from $0.130 \times 10^{7}$ to $35.9 \times 10^{7}$. There were significant differences between the CFU/mL in the biofilms treated with AA and control samples (Dunn's Multiple Comparison test, $\mathrm{p}<0.001$ ). Statistically significant differences in CFU/mL were present between the biofilms treated with UA and untreated after the $1^{\text {st }}, 2^{\text {nd }}$ and $3^{\text {rd }}$ day of incubation (Dunn's Multiple Comparison test, $\mathrm{p}<0.05$ )

\section{Discussion}

The search for alternative methods of treatment of infections caused by antibiotic-resistant bacteria is a major challenge of medicine today. Currently, an increased interest can be observed in plant compounds that can be used to support the standard therapy or to prevent bacterial and fungal infections. Among others, pentacyclic triterpenes are being intensively examined due to their multiple pharmaceutical activities combined with relatively low toxicity to eukaryotic cells. ${ }^{2-6}$

The MICs of AA were 64 or $128 \mu \mathrm{g} / \mathrm{mL}$ for all studied strains. Similarly, Taemchuay et al. showed that the
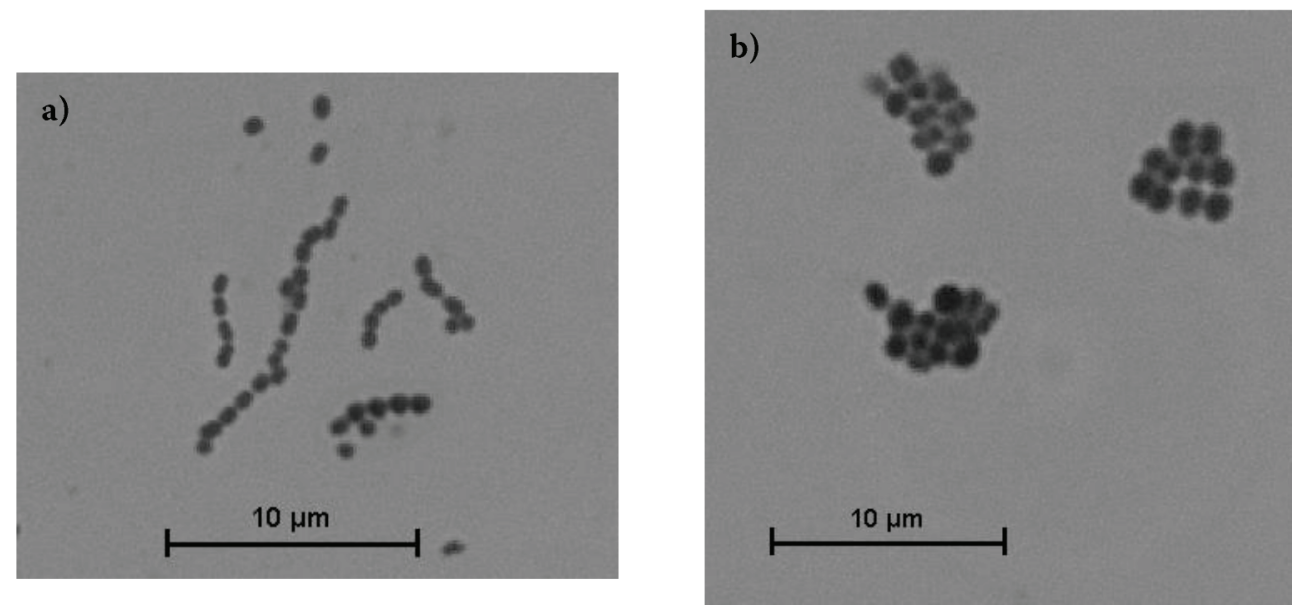

Fig. 3. Effect of asiatic acid on size and arrangement of the cells of E. faecalis strains; a) bacteria untreated, b) bacteria treated with AA. Magnification x1000 
Fig. 4. Effect of asiatic acid (AA) and ursolic acid (UA) on synthesis of a) lipase; b) lecithinase; c) hemolysin; d) gelatinase by E. faecalis clinical strains. Dunn's Multiple Comparison test, ${ }^{*} p<0.05 ;{ }^{* *} p<0.001$
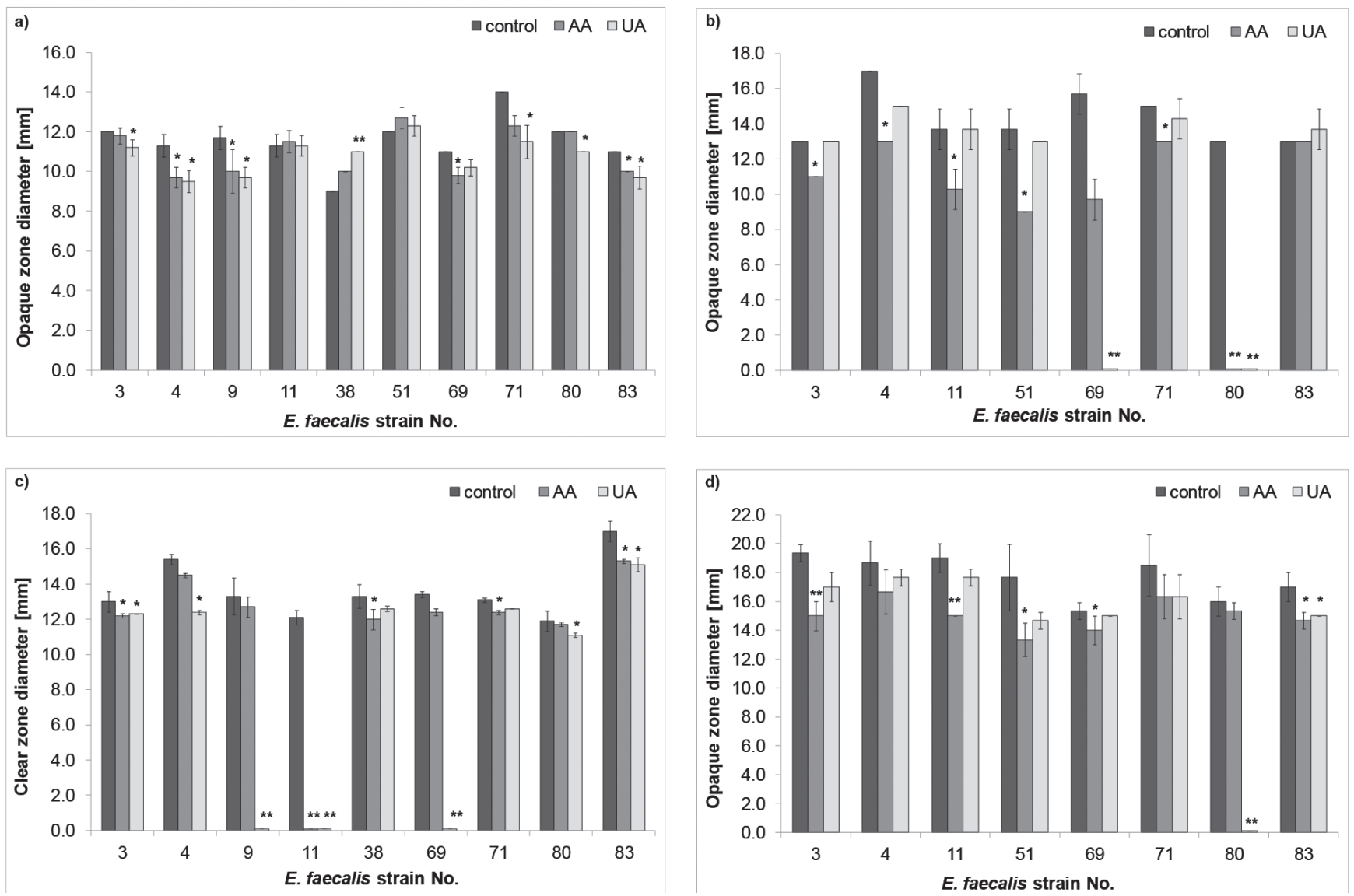

MIC values of AA against Staphylococcus aureus ranged from 20 to $160 \mu \mathrm{g} / \mathrm{mL} .{ }^{29}$ In contrast to our results, Liu et al. showed the MICs of AA against gram-positive (E. faecalis, S. aureus, Listeria monocytogenes and Bacillus cereus) and gram-negative (Escherichia coli, Salmonella typhimurium and Pseudomonas aeruginosa) bacteria were significantly lower and ranged from $20 \pm 2$ to $36 \pm 4 \mu \mathrm{g} / \mathrm{mL} .{ }^{30}$ The differences in MICs may be caused by differences in methods used for MIC value determination, different species of tested bacteria and various sources of origin of these microorganisms. In contrast to results obtained by Horiuchi et al., the MIC values of UA in our study were much higher and for different strains ranged from 32 to $512 \mu \mathrm{g} / \mathrm{mL} .{ }^{31}$ Our results are similar to those published by Fontanay et al., who established that the MIC values of UA against clinical strains of E. faecalis and S. aureus were $\geq 256 \mu \mathrm{g} / \mathrm{mL} .{ }^{32}$ However, the results of Horiuchi et al. as well as our previous studies have shown that the MICs of AA and UA against gram-negative bacteria were higher than the MICs for gram-positive strains. ${ }^{10-12,31}$ Such discrepancy is associated with the structural differences between the cell walls of these 2 types of bacteria. Gram-negative bacteria have an outer membrane with lipopolysaccharide in its

outer leaflet and phospholipids in the inner leaflet. This specific structure is an effective barrier protecting gramnegative rods from chemical factors. ${ }^{33}$

Our results showed that UA has better anti-growth activity to planktonic forms of E. faecalis than AA. Kim et al. have also demonstrated that UA used in a sub-inhibitory concentration $(0.5 \times \mathrm{MIC})$ reduced the survival of planktonic forms of the oral Streptococcus sobrinus strain. ${ }^{34}$ Such activity of UA may be related to the differences in the chemical structure of the examined triterpenes (Fig. 1). The number of hydroxyl and methyl groups is different in AA and UA. It should be noted that AA has 6 methyl groups attached to $\mathrm{C} 4, \mathrm{C} 8, \mathrm{C} 10, \mathrm{C} 14, \mathrm{C} 19$, and $\mathrm{C} 20$. UA contains one more methyl group (in the $\mathrm{C} 4$ position), therefore is more hydrophobic than AA. Moreover, Broniatowski et al. have found that pentacyclic triterpene acids interact with the phospholipids of bacterial membranes..$^{35}$ In particular, UA disintegrates cardiolipin-rich domains present in membranes, which can lead to the destruction of bacterial cells and their death.

The alterations of the size and arrangement of bacterial cells found in our research were similar to those observed by Ramirez-Arcos et al. for $E$. faecalis strains with a mutation in a gene encoding for a protein responsible for cell di- 
Fig. 5. Effect of asiatic acid (AA) and ursolic acid (UA) on a) biofilm formation and b) bacterial survival. Values represent the mean \pm SD of 3 separate experiments for ten E. faecalis clinical strains. Dunn's Multiple Comparison test, ${ }^{*} p<0.05$; ${ }^{* *} p<0.001$
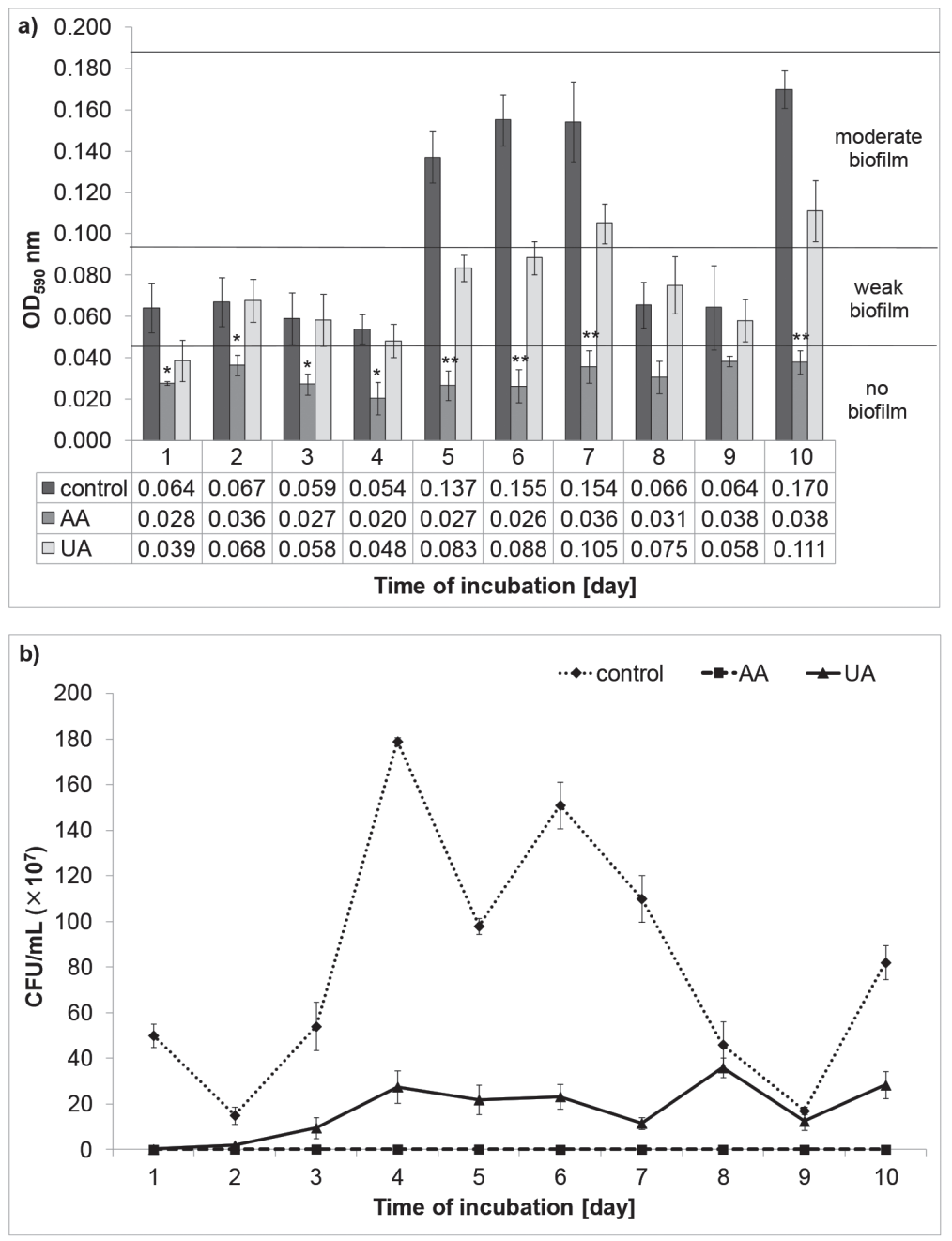

and causes its dysfunction. ${ }^{30}$ Also, Broniatowski et al. indicated that UA may incorporate into the bacterial membrane leading to its structural and functional alterations. ${ }^{35}$ Cell membrane damage may impair the transport of enzymes and toxins from the bacteria to the external environment. Therefore, our results showed that secretion of lipase, lecithinase, gelatinase, DNase and hemolysin by E. faecalis strains decreased after incubation with AA or UA. No other articles have been published regarding the antibacterial activity of pentacyclic triterpenes on bacterial protein secretion, therefore there was no possibility to compare our results with others.

Pathogenic microorganisms rarely exist as single cells. Bacteria usually form biofilms consisting of exopolysaccharide-surrounded microcolonies. Pathogens growing in a biofilm mass are a serious threat to human health because of their resistance to immune system factors and antibiotics. The better anti-biofilm activity of AA than UA might be associated with the chemical nature of these acids. AA possesses 3 hydroxyl groups $(C 2, C 3, C 23)$ that make it hydrophilic. UA has only one hydroxyl group (C3) and therefore is hydrophobic. Probably due to its hydrophilic nature, AA better penetrates into biofilm structures. The influence of UA on biofilm formation has been reported by other researchers. ${ }^{8,9}$ Ren et al. found that UA inhibited biofilm formation in gram-negative E. coli, Pseudomonas aeruginosa and Vibrio harveyi strains when added to inoculum or to $24 \mathrm{~h}$ biofilms. ${ }^{8}$ Zhou et al. noticed that 0.25 ÍMIC of UA

vision and chromosome segregation. ${ }^{36}$ It was demonstrated that abnormal chromosome segregation and disruptions of cell division can cause the phenotypic changes in the cells morphology e.g. increase the cell diameter and the occurrence of irregular groupings of cells. Therefore, it can be assumed that AA interferes with cell division processes.

The first step in the pathogenesis of UTIs is adhesion of the microorganism to host tissues. One of the important factors involved in this process is the hydrophobic character of the bacterial cell surface. ${ }^{10}$ The current research has shown no activity of both pentacyclic triterpenes on cell surface hydrophobicity. Our previous study showed that the impact of AA and UA on this virulence factor of clinical $E$. coli rods was very weak. ${ }^{10}$

Another important mechanism in the pathogenesis of UTIs is very likely associated with the secretion by bacteria of the host's tissue-damaging extracellular enzymes (e.g. lipases, lecithinase, gelatinase, DNase) and toxins (e.g. hemolysins). ${ }^{37}$ They belong to proteins which can be transported across the plasma membrane. ${ }^{38}$ Liu et al. established that AA destroys the cell membrane integrity affected biofilm production by gram-positive Streptococcus mutans and Streptococcus gordonii, while lower concentrations of this pentacyclic triterpene $(0.125 \times$ MIC and $0.0625 \times$ MIC) weakly inhibited biofilm development. ${ }^{9}$

The survival of E. faecalis in biofilm mass decreased after the treatment in both triterpenes. Garo et al. evaluated that AA applied alone did not reduce the cell viability of $P$. aeruginosa biofilms. However, this pentacyclic triterpene increased the susceptibility of biofilm bacteria to antibiotics. ${ }^{39}$

Based on the results obtained, we can assume that the triterpenes investigated should be considered natural components of a human diet rather than as antibacterial agents used on their own.

\section{References}

1. Jäger S, Trojan H, Kopp T, Laszczyk MN, Scheffler A. Pentacyclic triterpene distribution in various plants - rich sources for a new group of multi-potent plant extracts. Molecules. 2009;14:2016-2031.

2. Somova LO, Nadar A, Rammanan P, Shode FO. Cardiovascular, antihyperlipidemic and antioxidant effect of oleanolic acid and ursolic acid in experimental hypertension. Phytomedicine. 2003;10:115-121. 
3. Sultana T, Rashid MA, Ali MA, Mahmood SF. Hepatoprotective and antibacterial activity of ursolic acid extracted from Hedyotis corymbosa L. Bangladesh J Sci Ind Res. 2010;45:27-34.

4. Krishnamurthy RG, Senut MC, Zemke D, et al. Asiatic acid, a pentacyclic triterpene from Centella asiatica, is neuroprotective in a mouse model of focal cerebral ischemia. J Neurosci Res. 2009;87:2541-2550.

5. Shanmugam MK, Dai X, Kumar AP, Tan BK, Sethi G, Bishayee A. Ursolic acid in cancer prevention and treatment: Molecular targets, pharmacokinetics and clinical studies. Biochem Pharmacol. 2013;85:1579-1587.

6. Tsai SJ, Yin MC. Antioxidative and anti-inflammatory protection of oleanolic acid and ursolic acid in PC12 cells. J Food Sci. 2008;73:174-178.

7. Kurek A, Grudniak AM, Szwed M, et al. Oleanolic acid and ursolic acid affect peptidoglycan metabolism in Listeria monocytogenes. Anton Leeuw Int J G. 2010;97:61-68.

8. Ren D, Zuo R, Gonzalez Barrios AF, Bedzyk LA, Eldridge GR, Pasmore ME, Wood TK: Differential gene expression for investigation of Escherichia coli biofilm inhibition by plant extract ursolic acid. Appl Environ Microbiol 2005, 71, 4022-4034.

9. Zhou L, Ding Y, Chen W, Zhang P, Chen Y, Lv X. The in vitro study of ursolic acid and oleanolic acid inhibiting cariogenic microorganisms as well as biofilm. Oral Dis. 2013;19:494-500.

10. Wojnicz D, Kicia M, Tichaczek-Goska D. Effect of asiatic and ursolic acids on morphology, hydrophobicity and adhesion of UPECs to uroepithelial cells. Folia Microbiol. 2013;58:245-252.

11. Wojnicz D, Tichaczek-Goska D, Kicia M. Effect of asiatic and ursolic acids on growth and virulence factors of uropathogenic Escherichia coli strains. Turk J Biol. 2013;37:556-564.

12. Wojnicz D, Tichaczek-Goska D, Kicia M. Pentacyclic triterpenes combined with ciprofloxacin help to eradicate the biofilm formed in vitro by Escherichia coli. Indian J Med Res. 2015;141:343-353.

13. Rathnayake IU, Hargreaves M, Huygens F. Antibiotic resistance and virulence traits in clinical and environmental Enterococcus faecalis and Enterococcus faecium isolates. Syst Appl Microbiol. 2012;35:326-333.

14. Zhu X, Wang Q, Zhang C, Cheung GS, Shen Y. Prevalence, phenotype, and genotype of Enterococcus faecalis isolated from saliva and root canals in patients with persistent apical periodontitis. J Endod. 2010;36:1950-1955.

15. Clinical and Laboratory Standards Institute. Performance Standards for Antimicrobial Susceptibility Testing; Twenty-fourth Informational Supplement. CLSI Publication M100-S24, Vol. 34, No. 1. Wayne, PA, USA. Clinical and Laboratory Standards Institute, 2014.

16. European Committee on Antimicrobial Susceptibility Testing (EUCAST). Breakpoint tables for interpretation of MICs and zone diameters, version 5.0, 2015

17. Cosentino S, Podda GS, Corda A, Fadda ME, Deplano M, Pisano MB. Molecular detection of virulence factors and antibiotic resistance pattern in clinical Enterococcus faecalis strains in Sardinia. J Prev Med Hyg. 2010;51:31-36.

18. Creti $R$, Imperi $M$, Bertuccini $L$, et al. Survey for virulence determinants among Enterococcus faecalis isolated from different sources. J Med Microbiol. 2004;53:13-20.

19. Lindahl M, Faris A, Wadström T, Hjertén S. A new test based on 'salting out' to measure relative surface hydrophobicity of bacterial cells. Biochim Biophys Acta. 1981;677:471-476.

20. Furumura MT, Figueiredo PMS, Carbonell GV, Darini AL, Yano T. Virulence-associated characteristics of Enterococcus faecalis strains isolated from clinical sources. Braz J Microbiol. 2006;37:230-236.
21. Harrigan WF. Laboratory Methods in Food Microbiology. San Diego, CA: Academic Press. 1998.

22. Russell FM, Biribo SSN, Selvaraj G, et al. As a bacterial culture medium, citrated sheep blood agar is a practical alternative to citrated human blood agar in laboratories of developing countries. J Clin Microbiol. 2006;44:3346-3351.

23. Zeng J, Teng F, Murray BE. Gelatinase is important for translocation of Enterococcus faecalis across polarized human enterocytelike T84 cells. Infect Immun. 2005;73:1606-1612.

24. Szewczyk EM. Bacteriological diagnostics. Warsaw, Poland: PWN; 2011.

25. O'Toole GA, Kolter R. Flagellar and twitching motility are necessary for Pseudomonas aeruginosa biofilm development. Mol Microbiol. 1998;30:295-304.

26. Stepanovic S, Vukovic D, Hola V, et al. Quantification of biofilm in microtiter plates: overview of testing conditions and practical recommendations for assessment of biofilm production by staphylococci. Acta Path Micro Im B. 2007;115:891-899.

27. Di Bonaventura G, Spedicato I, D'Antonio D, Robuffo I, Piccolomini R. Biofilm formation by Stenotrophomonas maltophilia modulation by quinolones, trimetoprim-sulfamethoxazole, and ceftazidime. Antimicrob Agents Chemother. 2004;48:151-160.

28. Al-Talib H, Zuraina N, Kamarudin B, Yean CY. Genotypic variations of virulent genes in Enterococcus faecium and Enterococcus faecalis isolated from three hospitals in Malaysia. Adv Clin Exp Med. 2015;24:121-127.

29. Taemchuay D, Rukkwamsuk T, Sakpuaram T, Ruangwises N. Antibacterial activity of crude extracts of Centella asiatica against Staphylococcus aureus in bovine mastitis. Kasetsart Veterinarians. 2009;19:119-128.

30. Liu WH, Liu TC, Mong MC. Antibacterial effects and action modes of asiatic acid. Biomedicine. 2015;5:22-29.

31. Horiuchi K, Shiota S, Hatano T, Yoshida T, Kuroda T, Tsuchiya T. Antimicrobial activity of oleanolic acid from Salvia officinalis and related compounds on vancomycin-resistant enterococci (VRE). Biol Pharm Bull. 2007;30:1147-1149.

32. Fontanay S, Grare M, Mayer J, Finance C, Duval RE. Ursolic, oleanolic and betulinic acids: Antibacterial spectra and selectivity indexes. J Ethnopharmacol. 2008;120:272-276.

33. Ford M. Medical Microbiology. Oxford, UK: Oxford University Press; 2014.

34. Kim MJ, Kim CS, Park JY, et al. Antimicrobial effects of ursolic acid against mutans streptococci isolated from Koreans. Int J Oral Biol. 2011;36:7-11.

35. Broniatowski M, Flasiński M, Zięba K, Miśkowiec P. Interactions of pentacyclic triterpene acids with cardiolipins and related phosphatidylglycerols in model systems. Biochim Biophys Acta. 2014;1838:2530-2538.

36. Ramirez-Arcos S, Liao M, Marthaler S, Rigden M, Dillon JA. Enterococcus faecalis divIVA: An essential gene involved in cell division, cell growth and chromosome segregation. Microbiology. 2005;151:1381-1393.

37. Tsikrikonis G, Maniatis AN, Labrou M, et al. Differences in biofilm formation and virulence factors between clinical and fecal enterococcal isolates of human and animal origin. Microb Pathog. 2012;52:336-343.

38. Schneewinda O, Missiakas D. Sec-secretion and sortase-mediated anchoring of proteins in gram-postive bacteria. Biochim Biophys Acta. 2014;1843:1687-1697.

39. Garo E, Eldridge GR, Goering MG, et al. Asiatic acid and corosolic acid enhance the susceptibility of Pseudomonas aeruginosa biofilms to tobramycin. Antimicrob Agents Chemother. 2007;51:1813-1817. 